\title{
PREVALENCE OF HELICOBACTER PYLORI IS STILL HIGH AMONG SYMPTOMATIC BULGARIAN CHILDREN
}

\author{
LyUdMILA BOYANOVA ${ }^{1 *}$, PETYO HADZhIYSKI ${ }^{2}$, RUMYANA MaRKovSKA ${ }^{1}$, \\ PenKa Yaneva ${ }^{2}$, Daniel Yordanov ${ }^{1}$, Galina Gergova ${ }^{1}$ and IVAN Mitov ${ }^{1}$ \\ ${ }^{1}$ Department of Medical Microbiology, Medical University of Sofia, Sofia, Bulgaria \\ ${ }^{2}$ Specialized Hospital for Active Pediatric Treatment, Medical University of Sofia, \\ Sofia, Bulgaria
}

(Received: 22 August 2018; accepted: 12 November 2018)

\begin{abstract}
Helicobacter pylori positivity was assessed among 656 symptomatic children in 2010-2017. Overall infection prevalence was $24.5 \%$ and a significantly higher rate was detected in girls $(28.5 \%)$ compared to boys $(20.0 \%)$. Moreover, in children with duodenal ulcer, H. pylori prevalence was higher (47.4\%) compared with the rest (23.9\%). On the contrary, the infection was detected 1.9-fold less frequently in patients with GERD (14.5\%) compared with the other (27.0\%) patients and 2.1-fold less often in the presence of duodenogastric reflux (bile) reflux (13.0\%) compared with the absence of the reflux (27.0\%). No significant difference was observed between the younger (aged $\leq 7$ years, 20.0\%) and the older (aged 8-18 years, 25.5\%) patients. H. pylori infection rate in Bulgarian pediatric patients between 2010 and 2017 was 2.5-fold lower than that in 1996-2006. In conclusion, H. pylori infection is still an important concern for Bulgarian children, although having decreased by about $1.8 \%$ yearly over 21 years. This study reveals the importance of $H$. pylori diagnostics even in the youngest symptomatic children and demonstrates an inverse association between either GERD or bile reflux and H. pylori infection.
\end{abstract}

Keywords: Helicobacter pylori, infection, children, Bulgarian, peculiarities

\section{Introduction}

Helicobacter pylori infection is a common chronic infection affecting about half of human population worldwide and is most often acquired in early childhood $[1,2]$. Among children, prevalence of the infection widely varies from $<10 \%$ in some developed countries such as Sweden and Germany to $\geq 57 \%$ in other (mostly developing) countries such as India and Bangladesh [2]. In Bulgarian children

*Corresponding author; E-mail: 1.boyanova@hotmail.com 
aged 1-3 years, the seroprevalence of the infection was $13.5 \%$ [3]. Importantly, the infection persists lifelong if not successfully eradicated, thus carrying risks of ulceration or malignancy [4]; therefore, H. pylori diagnostics is of high importance to the healthcare.

The aim of this study was to evaluate $H$. pylori positivity in a large number ( $>650)$ of symptomatic Bulgarian children over 8 years and to assess factors associated with the infection.

\section{Material and Methods}

H. pylori positivity of 656 untreated symptomatic children (365 girls and 300 boys, 109 children aged $\leq 7$ years, and 547 aged $8-18$ years) was evaluated in 2010-2017. The characteristics of the pediatric patients are presented in Table I.

Biopsy sampling and strain isolation were performed as described in a previous publication [5]. Briefly, the gastric biopsy specimens were transported in Stuart transport medium (Liofilchem, Italy). The specimens were homogenized with sterile needles and used for direct Gram staining with carbol fuchsine, a rapid urease test with 10\% urea and for culture on both non-selective (Mueller-Hinton agar, Oxoid, UK, with 5\% sheep blood), and selective media (Columbia agar base, Liofilchem, with 5\% sheep blood and Dent's supplement). Plates were incubated in microaerophilic atmosphere (CampyGen, Oxoid) at $37{ }^{\circ} \mathrm{C}$ for $3-10$ days.

Table I. $H$. pylori positivity in Bulgarian symptomatic children

\begin{tabular}{|c|c|c|c|c|c|c|}
\hline Groups & Subgroups & $\begin{array}{c}\text { No. of } \\
\text { patients } \\
\text { evaluated }\end{array}$ & $\begin{array}{l}\text { No. of } \\
\text { H. pylori- } \\
\text { positive }\end{array}$ & $\begin{array}{c}\% \text { of } \\
\text { H. pylori- } \\
\text { positive }\end{array}$ & {$[95 \% \mathrm{CI}]$} & $p$ value \\
\hline \multirow[t]{2}{*}{ Sex } & Girls & 356 & 101 & 28.5 & [23.9-33.3] & $0.013 *$ \\
\hline & Boys & 300 & 60 & 20.0 & [15.8-24.9] & \\
\hline \multirow[t]{2}{*}{ Age } & $0-7$ years & 109 & 22 & 20.0 & [13.7-28.7] & 0.247 \\
\hline & $8-18$ years & 547 & 139 & 25.5 & [21.9-29.2] & \\
\hline \multicolumn{7}{|c|}{ Diseases/symptoms ${ }^{\mathrm{a}}$} \\
\hline \multirow[t]{2}{*}{ Duodenal ulcer } & Yes & 19 & 9 & 47.4 & [27.3-68.3] & $0.019^{*}$ \\
\hline & No & 637 & 152 & 23.9 & {$[20.7-27.3]$} & \\
\hline \multirow[t]{2}{*}{ GERD } & Yes & 131 & 19 & 14.5 & {$[9.4-21.6]$} & $0.003 *$ \\
\hline & No & 525 & 142 & 27.0 & [23.4-31.0] & \\
\hline \multirow[t]{2}{*}{ DGR } & Yes & 115 & 15 & 13.0 & {$[8.0-20.5]$} & $0.0016^{*}$ \\
\hline & No & 541 & 146 & 27.0 & {$[23.2-30.7]$} & \\
\hline Total & All & 656 & 161 & 24.5 & & \\
\hline
\end{tabular}

Note: CI: confidence interval; RAP: recurrent abdominal pain; DGR: duodenogastric reflux (bile reflux); GERD: gastroesophageal reflux disease.

${ }^{\mathrm{a}}$ Diseases/findings.

*Statistically significant difference. 
Identification was made by Gram staining of the colonies, lack of aerobic growth on blood agar plates, and testing for urease, oxidase, and catalase. H. pylori positive status was defined when culture or both direct staining and rapid urease test were positive. In our prior study in adults [6], the accuracy of culture was very high $(>95 \%)$ [7].

Written informed consent was received from the parents of the children. The study was approved by the ethics committee of the Medical University of Sofia, Sofia, Bulgaria.

\section{Statistical analysis}

Chi-square test and Fisher's exact test of independence were performed to compare variables of interest. Differences between groups were considered statistically significant, if $p$ values were $<0.05$. In addition, $95 \%$ confidence intervals ( $95 \% \mathrm{CIs})$ of the groups were calculated.

\section{Results}

Overall frequency of $H$. pylori infection was $24.5 \%$ (161/656 children). The frequency was significantly higher in girls $(28.5 \%)$ compared with boys $(20.0 \%$, $p=0.013$; Table I).

The infection was 3.3-fold more common in patients with duodenal ulcer (47.4\%) compared with those with gastroesophageal reflux disease (GERD, $14.5 \%, p=0.0006$ ). On the contrary, the positivity was 2.1 -fold less prevalent in children with duodenogastric reflux (DGR, bile reflux, 13.0\%, 15/115) compared with those without the reflux $(27.0 \%, 146 / 541, p=0.0016)$.

According to the age groups, $20 \%(22 / 109)$ of the patients aged $\leq 7$ years and $25.5 \%(139 / 547, p=0.247)$ of those aged $8-18$ years were $H$. pylori-positive. The youngest $H$. pylori-negative patient was aged 11 months and the youngest H. pylori-positive child was aged 1 year 7 months. Totally, two (18.2\%) of 11 patients aged $\leq 2$ years were $H$. pylori-positive.

\section{Discussion}

The overall frequency (24.5\%) of $H$. pylori infection in Bulgarian symptomatic children was 1.9-fold higher than that in pediatric patients $(13.0 \%)$ from USA [8] and our neighboring country, Greece (13.2\%) [9], and was 1.9-fold lower than that in Colombian symptomatic children (47\%), [10] and those (81.6\%) in a Spanish study of Aguilera-Correa et al. [11]. 
Notably, the current prevalence of $H$. pylori infection in the Bulgarian pediatric patients was 2.5 -fold lower than that $(61.7 \%)$ found in our previous study, using the same methods, in 1996-2006 [7]. The result suggests a decline (of about $1.8 \%$ per year) in the infection rate in the symptomatic children over 21 years. Similarly, although smaller $(0.57 \%$ per year), decrease was found using serology in asymptomatic Bulgarian adults over 18 years [12]. The decrease can be explained by the so-called cohort phenomenon, i.e., lower acquisition of the infection during the recent decades compared with that in 20th century as a result of improved socioeconomic status, personal hygiene habits and facilities, national antibiotic consumption, and increasingly common therapy of symptomatic patients [13]. However, the problem of $H$. pylori infection is still very important, given that every fifth child aged $\leq 7$ years was positive.

In a meta-analysis, although overall sex differences in $H$. pylori infection rates in children have shown male dominance [14], in 32 European studies, the difference was not perceptible, showing an odds ratio (OR) and 95\% CI of 0.95 $[0.88,1.03]$ [14]. In contrast, the sex difference was high in nine studies from Africa with OR 1.27 [95\% CI: 1.04, 1.54] [14]. In this study, the girls were 1.42-fold more often $\mathrm{H}$. pylori-positive compared with the boys. In a metaanalysis [15], the male predominance of the infection has been detected only in adult patients but not in children, possibly because of different antibiotic usage. Indeed, the study of Smith et al. [16] revealed that women received about $67 \%$ more antibiotic prescriptions per general practice consultation than men.

Whether $H$. pylori infection is positively or inversely associated with GERD in pediatric patients is still a topic of controversy [17-19]. Almost half of the children with duodenal ulcer were $H$. pylori-positive versus only $14.5 \%$ of those with GERD, which can support the understanding about an inverse association between $H$. pylori infection and GERD $[1,17]$. However, it is noteworthy that $H$. pylori eradication is not a cause of GERD and does not exacerbate the disease [1]; therefore, treatment of the infection should not be avoided in this patient group.

The association between DGR (bile reflux) and H. pylori infection also remains a topic of controversy. Huang et al. [20] detected an inverse association in H. pylori positivity between patients with bile reflux gastritis (35.8\%) and those with gastric cancer (73.0\%), whereas Ma et al. [21] did not observe significant association between both diseases in children. In the study of Silva et al. [22], ursodeoxycholic acid did not influence $H$. pylori infection.

In this study, we found statistically significant 2.1 -fold lower $H$. pylori positivity in children with bile reflux compared with those without DGR. Bile reflux has been presented as yellow discoloration of the mucosa and has been associated with mucosal damage by bile salts and acids [20,23]. The results 
indirectly support the observation of Huang et al. [20] about the inhibitory effect of the bile on $H$. pylori.

\section{Conclusions}

Briefly, in 2010-2017, H. pylori infection rate in Bulgarian pediatric patients showed a sharp decrease compared with that in 1996-2006, but it is still a common infection affecting every fourth child, consulting the Department of Pediatric Gastroenterology of the specialized University hospital. The peculiarities of the infection in this study were the similar prevalence of infection in children younger than 8 years and in the older patients, the higher infection rate in girls compared with boys, and the lower prevalence in children with GERD or bile reflux compared with the other pediatric patients. H. pylori infection in Bulgaria is still an important issue.

\section{Conflict of Interest}

The authors declare no conflict of interest.

\section{References}

1. Malfertheiner, P., Megraud, F., O’Morain, C. A., Gisbert, J. P., Kuipers, E. J., Axon, A. T., Bazzoli, F., Gasbarrini, A., Atherton, J., Graham, D. Y., Hunt, R., Moayyedi, P., Rokkas, T., Rugge, M., Selgrad, M., Suerbaum, S., Sugano, K., El-Omar, E. M., European Helicobacter and Microbiota Study Group and Consensus panel: Management of Helicobacter pylori infection - The MaastrichtV/Florence Consensus Report. Gut 66, 6-30 (2017).

2. Ozbey, G., Hanafiah, A.: Epidemiology, diagnosis, and risk factors of Helicobacter pylori infection in children. Euroasian J Hepatogastroenterol 7, 34-39 (2017).

3. Yordanov, D., Boyanova, L., Markovska, R., Hadzhiyski, P., Gergova, G., Mitov, I.: Seroprevalence of Helicobacter pylori $\mathrm{IgG}$ and CagA IgG in Bulgarian children. C R Acad Bulg Sci 71, 1124-1129 (2018).

4. Ford, A. C., Forman, D., Hunt, R. H., Yuan, Y., Moayyedi, P.: Helicobacter pylori eradication therapy to prevent gastric cancer in healthy asymptomatic infected individuals: Systematic review and meta-analysis of randomized controlled trials. BMJ 348, g3174 (2014).

5. Boyanova, L., Gergova, G., Nikolov, R., Davidkov, L., Kamburov, V., Jelev, C., Mitov, I.: Prevalence and evolution of Helicobacter pylori resistance to 6 antibacterial agents over 12 years and correlation between susceptibility testing methods. Diagn Microbiol Infect Dis 60, 409-415 (2008).

6. Boyanova, L.: Detection of Helicobacter pylori infection in symptomatic Bulgarian adults. Clin Microbiol Infect 13, 908-914 (2007). 
7. Boyanova, L., Lazarova, E., Jelev, C., Gergova, G., Mitov, I.: Helicobacter pylori and Helicobacter heilmannii in untreated Bulgarian children over a period of 10 years. J Med Microbiol 56, 1081-1085 (2007).

8. Raj, P., Thompson, J. F., Pan, D. H.: Helicobacter pylori serology testing is a useful diagnostic screening tool for symptomatic inner city children. Acta Paediatr 106, 470-477 (2017).

9. Roka, K., Roubani, A., Stefanaki, K., Panayotou, I., Roma, E., Chouliaras, G.: The prevalence of Helicobacter pylori gastritis in newly diagnosed children with inflammatory bowel disease. Helicobacter 19, 400-405 (2014).

10. Rosero Lasso, Y. L., Arévalo-Jaimes, B. V., Delgado, M. P., Vera-Chamorro, J. F., García, D., Ramírez, A., Rodríguez-Urrego, P. A., Álvarez, J., Jaramillo, C. A.: Evaluation of Helicobacter pylori infection and clarithromycin resistance in strains from symptomatic Colombian children. J Pediatr Gastroenterol Nutr 67, 601-604 (2018).

11. Aguilera-Correa, J. J., Urruzuno, P., Barrio, J., Martinez, M. J., Agudo, S., Somodevilla, A., Llorca, L., Alarcón, T.: Detection of Helicobacter pylori and the genotypes of resistance to clarithromycin and the heterogeneous genotype to this antibiotic in biopsies obtained from symptomatic children. Diagn Microbiol Infect Dis 87, 150-153 (2017).

12. Yordanov, D., Boyanova, L., Markovska, R., Ilieva, J., Andreev, N., Gergova, G., Mitov, I.: Helicobacter pylori seroprevalence in Bulgaria over 18 years and anti-CagA seroprevalence. C R Acad Bulg Sci 69, 1651-1658 (2016).

13. Iwańczak, B. M., Buchner, A. M., Iwańczak, F.: Clinical differences of Helicobacter pylori infection in children. Adv Clin Exp Med 26, 1131-1136 (2017).

14. Ibrahim, A., Morais, S., Ferro, A., Lunet, N., Peleteiro, B.: Sex-differences in the prevalence of Helicobacter pylori infection in pediatric and adult populations: Systematic review and meta-analysis of 244 studies. Dig Liver Dis 49, 742-749 (2017).

15. de Martel, C., Parsonnet, J.: Helicobacter pylori infection and gender: A meta-analysis of population-based prevalence surveys. Dig Dis Sci 51, 2292-22301 (2006).

16. Smith, D. R. M., Dolk, F. C. K., Smieszek, T., Robotham, J. V., Pouwels, K. B.: Understanding the gender gap in antibiotic prescribing: A cross-sectional analysis of English primary care. BMJ Open 8, e020203 (2018).

17. Lupu, V. V., Ignat, A., Ciubotariu, G., Ciubară, A., Moscalu, M., Burlea, M.: Helicobacter pylori infection and gastroesophageal reflux in children. Dis Esophagus 29, 1007-1012 (2016).

18. Kalach, N.: Gastroesophageal Reflux Disease and Helicobacter pylori in Children. In Vandenplas, Y. (ed): Gastroesophageal Reflux in Children. Springer, Cham, 2017, pp. 251-268.

19. Eren, M., Çolak, Ö., Işıksoy, S., Yavuz, A.: Effect of H. pylori infection on gastrin, ghrelin, motilin, and gastroesophageal reflux. Turk J Gastroenterol 26, 367-372 (2015).

20. Huang, H., Tian, J., Xu, X., Liang, Q., Huang, X., Lu, J., Yao, Y.: A study on the roles of Helicobacter pylori in bile reflux gastritis and gastric cancer. J BUON 23, 659-664 (2018).

21. Ma, M., Chen, J., Zhang, Y. Y., Li, Z. Y., Jiang, M. Z., Yu, J. D.: Pathogenic effects of primary duodenogastric reflux on gastric mucosa of children. Zhonghua Er Ke Za Zhi 46, 257-262 (2008).

22. Silva, J. G., Zeitune, J. M., Sipahi, A. M., Iryia, K., Laudanna, A. A.: Ursodeoxycholic acid does not interfere with in vivo Helicobacter pylori colonization. Rev Hosp Clin Fac Med Sao Paulo 55, 201-206 (2000).

23. Chang, W. K., Lin, C. K., Chuan, D. C., Chao, Y. C.: Duodenogastric reflux: Proposed new endoscopic classification in symptomatic patients. J Med Sci 36, 1-5 (2016). 